\title{
Effects of Relational Embeddedness and Innovative Opportunity on Intention to Cooperative Innovation
}

\author{
Liu Qun-hui ${ }^{1, a}, \quad$ Liu Er-li, b
}

'School of Law and Politics, Lingnan Normal University, Zhanjiang, 524048, China

${ }^{2}$ School of Management, Guangxi University for Nationalities, Nanning, 530006, China aemail:Iuquhu@126.com, 'email:8488643@qq.com

Keywords: Relational embeddedness; Innovative opportunity; Intention to cooperative innovation

\begin{abstract}
Based on the theory of social network, a theoretical model of the relationship between relational embeddedness, innovative opportunity and intention to cooperative innovation(ICI) was proposed. By using the data collected from 197 SMEs in Guangdong Province, the theoretical model is empirically tested. The results show that relational embeddedness has positive impacts on innovative opportunity and ICI; innovative opportunity has a positive impact on ICI and mediates the relationship between relational embeddedness and ICI.
\end{abstract}

\section{Introduction}

To innovate successfully, many high firms are collaborating with their extended networks of suppliers, customers, business partners and other organizations. In general, the cooperative innovation approach has been an important strategy for small and medium enterprises(SMEs) as a means to deal with increased uncertainty and complexity in the business setting and therefore become a sustainable competitive advantage. However, a lot of cooperative innovation practice in SMEs is not easily accomplished. In fact, about 50 percent of strategic alliances for SMEs failed (Lawrence et al.,2008). Owing to the short duration, unstable and high failure rate of the cooperation, the intention to cooperative innovation(ICI) of the SMEs is not strong as the theoretical expected (Atallah, 2005).

The ICI, is the preference and desire of the enterprise to adopt cooperative innovation activities (Ye, et al., 2004), which has an important impact on the success or failure on firm's cooperative innovation as well as the consistency. Scholars have studied the influences of the major issues and risk factors on ICI, such as income distribution, cost sharing, technology spillover, opportunism, complexity or change of technology, inter-firm coordination, etc. Some scholars using the resource based theory to explore the factors affecting the ICI of SMEs, such as Gulati(1999)、Ritter(2003) and Chen(2010), their studies pointed out that resources, internal technology and the excellent innovative talents are the important factors influencing the ICI of SMEs.

In addition, some studies underlined the impact of inter-firm commitment and mutual trust on ICI of enterprises (Emanuela,2012; Lin and Xue,2008). Krause, Handfield and Tyler(2007) found that mutual trust can enhance the awareness of cooperation and ICI, Li(2006) proposed that mutual trust between parties of the cooperative innovation alliance affect the firms' willingness to cooperate. According to Chen(2008) and Jian(2015), the relational embeddedness can help to promote the corporate willingness and performance. An empirical research study by Liu et al.(2014) demonstrated that the relational embeddedness has negative impacts on opportunistic behavior, and has positive impact on ICI of SMEs.

The present literature in the ICI of enterprises field has opened up a new realm of study on ICI from the perspective of relational embeddedness. In order to explore the relationship of ICI and relational embeddedness, it is necessary to propose a theoretical model of them and make an empirical analysis. The purpose of our research is to examine the relationship among ICI, relational embeddedness and innovative opportunity. In the following section, some assumptions will be developed. By using the data collected from 197 SMEs in Guangdong Province, the theoretical model is empirically tested. 


\section{Theory and development of hypotheses}

Enterprise must make full use of all embedded access to external network, and integrate available information about products, technology and markets with internal abilities so as to be more efficient to innovate.Relational embeddedness determines the quantity of resources, integrate and configure in the network, which also affect the organization behavior and performance of the enterprises (Granovetter,1992). Eenterprises have their own resources cooperate with the right firms can facilitate access to resources, and increase the probability of identifying innovative opportunities. In social networks, the strong relationship between enterprises will promote the dissemination of information, accelerate the flow of tacit knowledge, and thus provide more opportunities for technological innovation, which is also crucial to the cooperative innovation for enterprises. Thus, we hypothesize the following:

Hypothesis 1: Relational embeddedness has a positive effect on firm's innovation opportunity.

ICI reflects the degree of preference and willingness of a firm to cooperative innovation, it will be influenced by many factors, and the relational embeddedness is one of the most important factors.

In accordance with some scholars' ideas, firms which depend heavily on a relationship are more likely to interpret ambiguities in their partners' behaviors in a positive rather than a negative light (e.g., Murray, Holmes, and Griffin, 1996). High level of embedded may generate a high level of commitment to the relationship, thereby leading to the sharing of more detailed, systematic and specialized information, and effective conflict resolution(Kelley, 1979; Rusbult et al., 1991). Furthermore, it is conducive to the adoption of long term cooperation, and help to improve the efficiency of co-innovation and the willingness of cooperative innovation. This suggests the following hypothesis:

Hypothesis 2: Relational embeddedness has a positive effect on firm's ICI.

As the speed of technological revolution increases there will be an ever increasing number of opportunities that open up. Faced with the constant emergence of potential innovative opportunities, the firms will feel a lot of pressure to innovate. Opportunities for innovation are transient, missed them will widen the gap between firms with competitors and undoubtedly drive firms behind the competition. Therefore, enterprises must seize the favorable opportunities for innovation. However, enterprise's independent innovation ability is restricted so they must integrate with other organizations to carry out cooperative innovation if they want to convert this success into an opportunity. Therefore, the more innovative opportunities the enterprise faces, the stronger willingness to cooperate in the case of limited capacity of independent innovation. Thus, at this point we hypothesize that:

Hypothesis 3: Innovative opportunity has a positive effect on firm’s ICI.

\section{Method}

\subsection{Sample and Procedures}

The sample frame for this empirical study is SEMs that mainly distributed in the electronics and communications equipment manufacturing, information technology, bio-pharmaceutical, textile and other industries in Guangdong Province. A questionnaire was designed and mailed to 400 tech-managers or executive officer along with an informational letter stating the research purpose. The respondents should understand not only the business innovation strategy and industry trends, but also the process of cooperate innovation. They were asked to answer for their business enterprises. A total of 197 questionnaires were returned, leading to an effective response rate of 49.25\%.

The sample represents relatively newly founded SEMs. The rate of firms ranged from 5 to 10 years was 35.4\%, 3 to 5 years was 32.2\%. Only 13.5\% was over 10 years, and the rest was under 3 years. With a standard number of employees of 2,000, 58.9\% were small firms, and $41.1 \%$ were medium enterprise. According to the high-tech and traditional industry classification, the former rate was $50.25 \%$, and the latter rate was $49.75 \%$. 


\subsection{Measurement}

Measure development began with interviews and a field test of our instrument among technical and managerial staff in five small enterprises to ensure that our measures were relevant and our language was appropriate for target respondents. The final survey contained measures of the key constructs. We assessed all items on a five-point Lilert scale in which $1=$ "strongly disagree" and $5=$

“strongly agree” .These measures, intercorrelations, reliability and descriptive statistics are provided in Table 1.

Relational embeddedness. We assessed relational embeddedness by means of three most commonly discussed and also deemed key measures from Uzzi(1997) and Gulati(2007): trust, information sharing and problem solving.

Innovative opportunity. It is a factor with four indicators developed by Chen(2008): develop new products, find the merits and disadvantages of the product, find more new product development solutions, and find more process improvements.

Intention to cooperative innovation. To measure the variable, we use an index consisting six items developed by Zhang(2001): to obtain innovative resources, to improve the success rate of innovation, to improve the speed of innovation, to reduce the cost of innovation, to achieve common success, and to improve the technical level.

\section{Results}

\subsection{Result of reliability and validity test}

Reliability of the questionnaire was assessed by calculating Cronbach's alpha(which indicates reliability of the mean) for each of the three variables. The resulting Cronbach's alpha scores were all exceeded 0.70, which indicate good reliability(Table 1).

Table 1 Result of reliability and validity test

\begin{tabular}{|c|c|c|c|c|c|c|}
\hline & $\begin{array}{c}\text { Cronbachs' } \\
\alpha \\
\end{array}$ & $\begin{array}{c}\text { Mean } \\
\text { variance }\end{array}$ & Reliability & $\begin{array}{l}\text { Absolute } \\
\text { fit index }\end{array}$ & $\begin{array}{c}\text { Relative fit } \\
\text { index }\end{array}$ & parsimony fit index \\
\hline ICI & 0.880 & 0.551 & 0.880 & $\begin{array}{l}x^{2}=18.569 \\
d f=9 \\
G F I=0.969 \\
\text { RMR }=0.020 \\
\text { RMESA }=0.074\end{array}$ & $\begin{array}{l}\text { CFI }=0.983 \\
I F I=0.983 \\
\text { NFI }=0.968 \\
\text { RFI }=0.947\end{array}$ & $\begin{array}{l}\text { CAIC value: } \\
\text { Theoretical model } 93.968< \\
\text { saturated model } 31.947< \\
\text { independence model } \\
\text { 21.826, } x^{2} / \mathrm{df}=2.063, \\
\text { PNFI=0.581 }\end{array}$ \\
\hline $\mathrm{IO}$ & 0.939 & 0.799 & 0.940 & $\begin{array}{l}x^{2}=7.748 \\
d f=2 \\
G F I=0.98 \\
\text { RMR }=0.029 \\
\text { RMESA }=0.067\end{array}$ & $\begin{array}{l}\text { CFI }=0.987 \\
I F I=0.987 \\
\text { NFI }=0.982 \\
\text { RFI }=0.947\end{array}$ & $\begin{array}{l}\text { CAIC value: } \\
\text { Theoretical model } 58.01 \\
\text { <saturated model } 62.83 \\
\text { <independence model } \\
\text { 462.378, x²/df=3.874, } \\
\text { PNFI=0.681 }\end{array}$ \\
\hline $\mathrm{RE}$ & $\begin{array}{l}0.743 \\
0.857 \\
0.815\end{array}$ & 0.494 & 0.744 & $\begin{array}{l}x^{2}=62.140 \\
d f=41 \\
G F I=0.948 \\
\text { RMR }=0.030 \\
\text { RMESA }=0.051\end{array}$ & $\begin{array}{l}\mathrm{CFI}=0.981 \\
\mathrm{IFI}=0.981 \\
\mathrm{NFI}=0.946 \\
\mathrm{RFI}=0.927\end{array}$ & $\begin{array}{l}\text { CAIC value: } \\
\text { Theoretical model } \\
19.221<\text { saturated model } \\
\text { 414.691<independence } \\
\text { model } 1218.731 \text {, } \\
\mathrm{x}^{2} / \mathrm{df}=1.516, \text { PNFI=0.705 }\end{array}$ \\
\hline
\end{tabular}

(Notes: ${ }^{* * *} \mathrm{P}<.010$, ICI represents intention to cooperative innovation, IO represents innovative opportunity, RE represents relational embeddedness.)

Besides, through confirmatory factor analysis and correlative analysis, absolute fit index, relative fit index, and parsimony fit index basically meet the requirements, show that this questionnaire has good construct validity. The results are shown in Table 1.

\subsection{Descriptive statistical analysis of variables}

Descriptive statistics (means and S.D.) as well as the correlation matrix of all variables are presented in Table 2. The constructs were formed by taking the mean of their respective measurement items. 
Table 2 Means, standard deviations and correlations

\begin{tabular}{|c|c|c|c|c|c|c|}
\hline \multirow{2}{*}{ variable } & \multirow{2}{*}{ Mean } & \multirow{2}{*}{ Std. Deviation } & \multicolumn{4}{|c|}{ Pearson Correlations } \\
\cline { 4 - 7 } & & & 1 & 2 & 3 & 4 \\
\hline $\mathrm{Re}$ & 3.929 & 0.686 & -0.054 & 1.000 & & \\
\hline IO & 3.678 & 0.471 & -0.049 & $0.461^{* *}$ & 1.000 & \\
\hline ICI & 3.629 & 0.696 & -0.129 & $0.288^{* *}$ & $0.416^{* *}$ & 1.000 \\
\hline
\end{tabular}

(Notes: $* * \mathrm{P}<.010$.)

\subsection{Construction and test of the model}

In order to further verify the relationship between the variables, we uses Amos21.0 software to analyze the relationship between relational embeddedness, innovative opportunity and ICI by structural equation modeling. Figure 1 shows the measurement model of the above three variables. The ellipse represents the latent variable, the rectangle indicates the observation variable, and the e1-e17 are the error terms of the observation variables, and the D1-D3 are the residuals of the structural equation.

The set of structural equation testing results displayed in Table 3. The fitted index of structural equation modeling showed that absolute fit index RMR, RMSEA are acceptable, GFI and AGFI are slightly less than 0.900 (more than 0.800), which can be accepted. The incremental fit measures such as CFI, IFI and TLI are more than 0.900, NFI and RFI can be accepted. The parsimonious fit measures such as PNFI and PCFI more than 0.700, which can be accepted. Chi square degrees of freedom ratio is more than 1 and less than 2, achieved an acceptable level. The CAIC value of theory model is both less than that of saturated model and independent model. Overall, the model fit of the theoretical model is ideal, which can be used to test the theoretical hypothesis proposed in this paper.

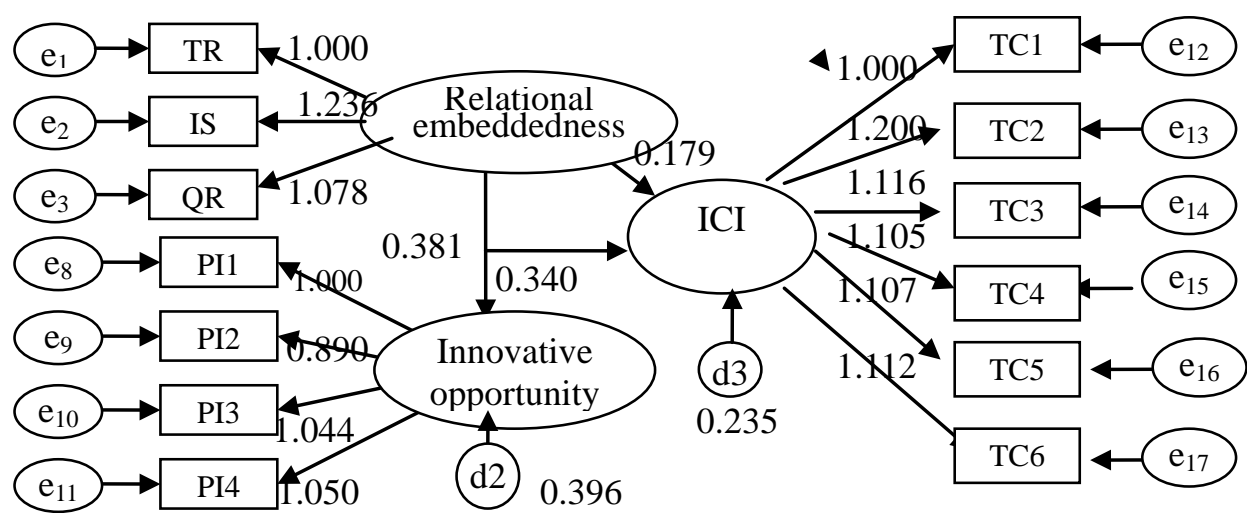

Figure 1 Overall theoretical model and path relationships

The key verified results of hypotheses are presented in Table III. Results indicate support for direct effects of relational embeddedness on ICI, the overall effect was positive, significant, and effect coefficient was $0.179(\mathrm{P}<0.010)$. Thus, $\mathrm{H} 2$ is supported. The effect coefficient of relationship embedding on innovative opportunity was $0.381(\mathrm{P}<0.001)$, which is significant and support our first hypothesis. As shown in Table III, the effect of innovative opportunity on ICI is also significant (effect coefficient $=0.340, \mathrm{P}<0.001$ ), thus $\mathrm{H} 3$ is supported. 
Table 3 Verified results of each model

\begin{tabular}{|c|c|c|c|c|}
\hline Effect path & $\begin{array}{c}\text { Effect } \\
\text { coefficient }\end{array}$ & Absolute fit index & $\begin{array}{l}\text { Incremental } \\
\text { fit index }\end{array}$ & parsimony fit index \\
\hline $\mathrm{IO} \leftarrow$ & $0.381^{* * *}$ & \multirow{3}{*}{\begin{tabular}{|l|}
$x^{2}=196.986$ \\
$d f=114$ \\
GFI $=0.896$ \\
AGFI $=0.861$ \\
RMR $=0.043$ \\
RMSEA $=0.061$ \\
\end{tabular}} & \multirow{3}{*}{$\begin{array}{c}C F I=0.946 \\
I F I=0.947 \\
\text { NFI }=0.882 \\
\text { RFI }=0.859 \\
\text { TLI }=0.935\end{array}$} & \multirow{3}{*}{$\begin{array}{l}\text { CAIC Value: } \\
\text { Theoretical model } 442.305< \\
\text { saturated model } 961.330< \\
\text { independence model } 1780.75 \\
\text { X }^{2} / \mathrm{df}=1.728, \mathrm{PNFI}=0.739, \\
\text { PCFI=0.793 }\end{array}$} \\
\hline $\mathrm{ICI} \leftarrow \mathrm{RE}$ & $0.179^{*}$ & & & \\
\hline $\mathrm{ICI} \leftarrow \mathrm{IO}$ & $0.340^{* * *}$ & & & \\
\hline
\end{tabular}

(Notes: $* * * \mathrm{P}<.001, * * \mathrm{P}<.010, * \mathrm{P} \leqslant .050$.)

\section{Conclusions}

The aim of this study was to test the effects of relational embeddedness and innovative opportunity on ICI. The results supported all hypotheses:(1) The degree of relational embeddedness appears to have a positive impact on a firm's innovative opportunity, (2) The presence of a high degree of relational embeddedness helps maintain a strong ICI, and (3) the more innovative opportunities the enterprise faces, the stronger willingness to cooperate in the case of limited capacity of independent innovation. Furthermore, our study reveals that the innovative opportunity played a mediating role in the relationship between relational embeddedness and ICI. These findings advance knowledge on the effects of relational embeddedness on innovative opportunity and ICI and hold important implications for both managerial practice and public policy.

Our findings imply that enterprise embedded well in the social network is beneficial to aggregate, absorb and integrate heterogeneity knowledge and other innovation resources, therefore bring more potential opportunities for innovation, and thus help to enhance the ICI. Our research suggests that innovative opportunity is associated with good social embedded, as well as strong ICI is supported by good embeddedness in industrial network. This means that SMEs should make full use of all embedded access to external network so as to be more efficient to innovate.

Perhaps the major limitation pertains to the breadth of our sample. Although our sample included a broad swath of industries, it focuses solely on Guangdong firms. Thus, additional research is needed to establish whether our patterns of effects are generalizable. In order to permit generalization, future research could make larger-scale investigation across the China country. In addition, future research could examine the moderating effect of firm ownership considering the China’s special condition.

\section{Acknowledgements}

Financial support for this work was provided by the Fund of Guangdong public welfare research and capacity building special project in 2014 (Grant Number 2014A070703060).

\section{References}

[1] Arnett D B, Macy B A, Wilcox J B. The Role of Core Selling Teams in Supplier-Buyer Relationships[J] .Journal of Personal Selling \& Sales Management, 2005, 25(1): 27-42

[2] Atallah G. R\&D cooperation with asymmetric spillovers [J]. Canadian Journal of Economics, 2005, 38(3):919-936

[3] Barden,J, Mitchell W. Disentangling the influences of leaders' relational embeddedness on inter-organizational exchange[J]. Academy of Management Journal,2007,50(6):1440-1461

[4] Cassiman B,Veugelers R. R\&D cooperation and spillovers: Some empirical evidence from Belgium[J]. American Economic Review,2002,92(4):1169-1184

[5] Chen D. Does inter-firm technological cooperation enhance innovation performance? An empirical Study of High-tech SMEs in China. International Journal of Innovation and 
Learning,2010,8(2):149-169

[6] Das, T.K. and Teng, Bing -Sheng. Risk types and interalliances structures[J].Journal of Management Studies, 1996, 33(6):827-843

[7] Doney P M, Cannon J P. An Examination of the Nature of Trust in Buyer Seller Relationships[J].Journal of Marketing, 1997, 61(2): 35- 51

[8] Friman M, Gärling T, Millett B et al. An analysis of international business to business relationship based on the commitment-trust theory [J].Industrial marketing management, 2002, 31:403-409

[9] Granovetter M. Economic action and social structure: The problem of embeddedness source[J].The American Journal of Sociology,1985,91(3):481-510

[10]Gulati R, Sytch M. Dependence asymmetry and joint dependence in inter-organizational relationships: Effects of embeddedness on a manufacturer' $s$ performance in procurement relationships[J]. Administrative Science Quarterly,2007,52:32-69

[11]HuSong Ding, Ping He, FuXiang Wu, et al. The impact of cooperation and competition on the performance of flexible decentralized manufacturing networks[J]. International Journal of Computational Intelligence Systems, 2013, 6(1):174-185.

[12]Jian Z., Liu Y. An Empirical Study on Effects of Relational Embeddedness, Network Competence and Service Innovation Performance. Soft Science, 2015,5:1-5

[13]Krause D R, Handfield R B, Tyler B B. The Relationships between Supplier Development, Commitment, Social Capital Accumulation and Performance Improvement[J].Journal of Operations Management, 2007, 25(2): 528-545

[14]Lawrence O, Charles G, Kristi C, et al. Collaborative innovation throughout the extended enterprise[J]. Strategy \& Leadership,2008,36(1):39-45

[15]Liu Q., Hu Y., Liu E. Relationships among Environmental Pressures, Entrepreneurs’ Network and Intention to Cooperative Innovation. Science Research Management,2014,12:103-111

[16]Liu Q., Li L. Relationships among Relational Embeddedness, Opportunistic Behavior and Intention to Cooperative Innovation_-An Empirical Study of SMEs Sample in Guangdong. Science of Science and Management of S.\& T. 2013,7:83-94

[17]Ritter T, Gemunden H G. Network competence: Its impact on innovation success and its antecedents[J].Journal of Business Research,2003,56(9):745-755

[18]Uzzi B. Social structure and competition in inter-firm networks: The paradox of embeddedness [J].Administrative Science Quarterly, 1997, 42:35-67 